\title{
Optimal fiscal policy with environmental tax and pollution-abatement spending in a model with utility-enhancing environmental quality: lessons from Bulgaria
}

\author{
Aleksandar Vasilev*
}

October 2, 2018

\begin{abstract}
This paper characterized optimal fiscal policy - with environmental taxes, and public spending on abatement - in the presence of pollution, and evaluated it relative to the exogenous (observed) one in Bulgaria, an economy with a largely unreformed and polluting industry. The results are evaluated in light of the optimal environmental taxation of dirty production and the optimal spending on abatement, and the effect of those fiscal measures on the utility-enhancing environmental quality. To this end, a dynamic general-equilibrium model is calibrated to Bulgarian data (1999-2016). The main findings from the computational experiments performed are: (i) The optimal steady-state income tax rate is zero; (ii) The benevolent Ramsey planner provides twenty percent higher utility- enhancing environmental quality; (iii) The optimal level of carbon taxes is almost three times higher, and the optimal level of abatement spending is six times higher; (iv) The optimal steady-state consumption tax is twice lower.
\end{abstract}

JEL classification: C68, Q2, Q4, Q54, Q58

\footnotetext{
*Lecturer, Lincoln International Business School, University of Lincoln, UK. Email:avasilev@ylincoln.ac.uk.
} 
Keywords: Ramsey policy, pollution, environmental quality, environmental tax 


\section{Introduction and Motivation}

Since the early 1990s, many macroeconomic studies have focused on the effects of observed fiscal policy in general equilibrium setups, and in particular comparing and contrasting it to a benchmark-, or "optimal fiscal policy" regime. ${ }^{1}$ The exercise was used to inform policymakers about the taxation and spending mix in public finances, and how it needs to be adjusted to improve allocative efficiency in the economy. The main focus of the computational experiments performed in those papers, however, has been predominantly on the effects of government purchases (consumption), public investment, and capital and labor taxes. One limitation of that literature is that it overemphasized the distinction between capital and labor income taxation, and abstracted away from consumption, or value-added, taxation (VAT). Furthermore, in Eastern Europe, there was also a move toward a common income tax rate, and reliance on indirect (consumption/VAT and excise) taxation. Such characteristics lead to a slightly different public finance problem, from the ones typically covered in the public finance literature. In particular, in addition to deciding on the optimal level of public spending, here the fiscal authority is also choosing two tax rates - a common income tax rate, and a tax rate on consumption.

Recently, there has been an intense discussion of environmental policy within the macroeconomic context, e.g. Fischer and Heutel (2013). The focus of this paper is the particular effects of this "environmental fiscal policy" within the paradigm of public finance macroeconomics. A suitable case study for the aggregate effects of environmental policies is Bulgaria, a former communist country, and a current EU member state. We will focus on the period after the introduction of the currency board arrangement (1999-2016), which is a period of macroeconomic stability. One aspect of the communist heritage was the over-reliance on heavy manufacturing, and the disregard of environmental norms. In particular, the energyintensive industry was a major polluter of the environment. Often pollution is a negative externality of industrial production, as producers often do not take it under consideration when choosing their output levels. Such external effects then necessitate government action to improve allocative efficiency through taxes and spending. The public finance setup, augmented with environmental fiscal policy, is an important variation from the classical

\footnotetext{
${ }^{1}$ For, example, Chari, Christiano and Kehoe $(1994,1999)$, and many others.
} 
approach described in Chari, Christiano and Kehoe (1994, 1999), and thus represents an important contribution to the literature, which could be of interest to policy-makers.

The paper then proceeds to characterize optimal (Ramsey) fiscal policy in the context of the problem described above and then to evaluate it relative to the exogenous (observed) fiscal policy regime. Similar to earlier literature, e.g. Judd (1985), Chamley (1986), and Zhu (1992), allowing distortionary taxation in a dynamic general-equilibrium framework creates interesting trade-offs: On the one hand, utility-enhancing environmental quality directly increase household's utility. On the other, the proportional income taxes and the environmental tax levied on production will negatively affect the incentives to supply labor and to accumulate physical capital. In turn, higher taxes reduce not only income, but also consumption, which is actually hit twice due to a second round of taxation, this time at the point of consumption. Both types of distortionary taxes lower welfare, both directly, and indirectly, by generating less tax revenue which could be spent on public abatement spending, which would increase the utility-enhancing environmental quality.

The optimal fiscal policy problem discussed in this paper is to choose consumption tax rate, a common income tax rate, an environmental tax rate to finance public spending on abatement and redistributive government transfers, while at the same time minimizing both the allocative distortions created in the economy, as a result of the presence of proportional taxation, and the pollution externality, which lowers the level of utility-enhancing environmental quality. The main findings from the computational experiments performed are: (i) The optimal steady-state income tax rate is zero; (ii) The benevolent Ramsey planner provides twenty percent higher utility-enhancing environmental quality; (iii) The optimal level of carbon taxes is almost three times higher, and the optimal level of abatement spending is six times higher; (iv) The optimal steady-state consumption tax is twice lower, as compared to the exogenous policy case.

The rest of the paper is organized as follows: Section 2 describes the model framework and defines the decentralized equilibrium system. Section 3 discusses the calibration procedure, and Section 4 presents the steady-state model solution. Sections 5 proceeds with 
the optimal taxation (Ramsey) policy problem, and evaluates the long-run effects on the economy. Section 6 concludes the paper.

\section{Model Description}

The model setup follows closely Vasilev (2018b). In particular, there is a representative household in the model economy, which derives utility out of consumption, leisure and environmental quality. On the production side, there is a stand-in firm, which produces a homogeneous final good, and pollution as a by-product, which in turn lowers the level of environmental quality. The government imposes a carbon tax on output, and in addition can spend on pollution abatement activities. The government also has access to consumption and income taxation, and returns the surplus revenue back to the household in a lump-sum fashion. The final good which could be used for consumption, investment, or government pollution abatement spending.

\section{$2.1 \quad$ Household}

The representative one-member household values consumption, leisure, and environmental quality:

$$
E_{0} \sum_{t=0}^{\infty} \beta^{t}\left\{\ln c_{t}+\theta \ln \left(1-h_{t}\right)+\gamma \ln q_{t}\right\}
$$

where $E_{0}$ is the expectations operator as of period $0,0<\beta<1$ is the discount factor, $c_{t}$ denotes household's consumption in period $t, h_{t}$ denote hours worked, and $q_{t}$ is preference for clean environment ("environment quality"). Parameter $\theta>0$ reflects the relative (to consumption) weight attached to leisure, while $\gamma>0$ denotes the relative weight that the household attaches to environment quality. As in in Angelopoulos et al. (2013), we define the last term as a "good" (or absence of pollution, hence "more is better"), and not as a "bad" (stock of pollution). This is done to preserve the positive monotonicity in household's preferences. In addition, environmental quality will possess all the features of a public good.

The household starts with an initial stock of physical capital $k_{0}>0$, and has to decide 
how much to add to it in the form of new investment. Every period physical capital depreciates at a rate $\delta^{k}$, where $0<\delta^{k}<1$. The law of motion for physical capital is then

$$
k_{t+1}=i_{t}+\left(1-\delta^{k}\right) k_{t}
$$

and the real interest rate is $r_{t}$, hence the before-tax capital income of household $i$ in period $t$ equals $r_{t} k_{t}$. The household also owns the firm in the economy, and has a legal claim on the firm's profit, $\pi_{t}$. In addition to capital income, each household can generate labor income by working in the representative firm. The hourly wage rate is $w_{t}$, so before-tax labor income equals $w_{t} h_{t}$. The household's budget constraint is as follows:

$$
\left(1+\tau_{t}^{c}\right) c_{t}+k_{t+1}-\left(1-\delta^{k}\right) k_{t}=\left(1-\tau_{t}^{y}\right)\left[w_{t} h_{t}+r_{t} k_{t}+\pi_{t}\right]+g_{t}^{t}
$$

where $\tau_{t}^{c}$ is the consumption tax rate, $\tau_{t}^{y}$ is the common (labor and capital) income tax rate, and $g_{t}^{t}$ denotes government lump-sum transfers.

The household takes initial capital stock $k_{0}$, environmental quality $\left\{q_{t}\right\}_{t=0}^{\infty}$, prices $\left\{w_{t}, r_{t}\right\}_{t=0}^{\infty}$, profits $\left\{\pi_{t}\right\}_{t=0}^{\infty}$, and policy variables $\left\{\tau_{t}^{c}, \tau_{t}^{y}, g_{t}^{t}\right\}_{t=0}^{\infty}$ as given, and chooses $\left\{c_{t}, h_{t}, k_{t+1}\right\}_{t=0}^{\infty}$ to maximize Eq. (2.1) s.t (2.2)-(2.3). The first-order optimality conditions (FOCs), and the boundary (transversality) condition for physical capital, are as follows:

$$
\begin{aligned}
c_{t} & : \frac{1}{c_{t}}=\lambda_{t}, \\
h_{t} & : \frac{\theta}{1-h_{t}}=\lambda_{t}\left(1-\tau_{t}^{y}\right) w_{t} \\
k_{t+1}: & \lambda_{t}=\beta E_{t} \lambda_{t+1}\left[1+\left(1-\tau_{t+1}^{y}\right) r_{t+1}-\delta^{k}\right] \\
T V C & : \lim _{t \rightarrow \infty} \beta^{t} \lambda_{t} k_{t+1}=0 .
\end{aligned}
$$

The interpretation of the conditions above is standard; The first FOC equates the marginal benefit from an additional unit of consumption and the shadow price of wealth. The second equation balances the disutility of labor and the benefit in terms of after-tax wage, and weighted by the price in terms of consumption. The third one is a dynamic optimality condition, which states how capital should be allocated in any two congruent periods. The last one is a boundary condition, imposed to rule out explosive solution paths. 


\subsection{Stand-in firm}

There is a representative firm in the economy, which produces a homogeneous product. Total production value is taxed at a rate $\tau_{t}^{E}$. The price of output is normalized to unity. The production technology is Cobb-Douglas and uses both physical capital and labor hours to maximize static profit

$$
\pi_{t}=\left(1-\tau_{t}^{E}\right) A k_{t}^{\alpha} h_{t}^{1-\alpha}-r_{t} k_{t}-w_{t} h_{t},
$$

where $A$ denotes the level of technology, and $\tau^{E}$ denotes the time-varying proportional environmental tax on revenue. In equilibrium, profit is zero $\left(\pi_{t}=0\right)$, and each input is priced according to its tax-adjusted marginal product, i.e.:

$$
\begin{aligned}
& k_{t}: \quad r_{t}=\left(1-\tau_{t}^{E}\right) \alpha \frac{y_{t}}{k_{t}}, \\
& h_{t}: \quad w_{t}=\left(1-\tau_{t}^{E}\right)(1-\alpha) \frac{y_{t}}{h_{t}} .
\end{aligned}
$$

The carbon/energy tax acts like a tax on inputs, and in many aspects similar to an income tax, but born by producer (like a payroll tax).

\subsection{Pollution and environmental quality}

In this paper, the stock of environmental quality is equivalent to "absence of pollution." As in Angelopoulos et al. (2013), and Economides and Phillipopulos (2007), environmental quality evolves according to the following law of motion:

$$
q_{t+1}=\left(1-\delta^{q}\right) \bar{q}+\delta^{q} q_{t}-p_{t}+\nu g_{t}^{E}
$$

where $\bar{q}>0$ denotes the steady-state stock of environmental quality, $0<\delta^{q}<1$ is the persistence parameter of environment quality. $p_{t}$ denotes the level of emitted pollution in period $t$, which decreases environmental quality. To offset the effect of pollution, government can spend resources on pollution abatement (cleanup policy), and the efficiency of that technology is captured by parameter $\nu>0$.

In the model, pollution $p_{t}$ is generated as a by-product of production, or, in other words:

$$
p_{t}=\phi y_{t}=\phi A k_{t}^{\alpha} h_{t}^{1-\alpha},
$$


where $0<\phi<1$ is the measure of the pollution technology that maps (say $\mathrm{CO}_{2}$ ) emissions as a function of aggregate output. Note that when we solve for the decentralized competitive equilibrium, the firm will maximize profit independently of the level of pollution emitted, and would produce a level of output that is larger than the socially optimal amount. In that sense, there will be a negative externality effect in the competitive equilibrium in the model, and the allocations will be inefficient.

\subsection{Government}

In the model setup, the government is levying taxes on labor and capital income, taxes production, as well consumption in order to its finance spending on transfers and pollutiondecreasing (abatement) activities. The government budget constraint is as follows:

$$
g_{t}^{t}+g_{t}^{E}=\tau_{t}^{c} c+\tau_{t}^{E} y+\tau_{t}^{y}\left[w_{t} h_{t}+r_{t} k_{t}\right]
$$

Government spending on abatement-to-output ratio would be chosen to match the average share in data, and government transfers would be determined residually in each period so that the government budget is always balanced. ${ }^{2}$

\subsection{Dynamic Competitive Equilibrium (DCE)}

For the given values of the technology parameters $\{A, \phi\}$, average tax rates $\left\{\tau^{c}, \tau^{y}, \tau^{E}\right\}$, initial capital stock $k_{0}$, initial environmental quality $\left\{q_{0}\right\}$, the decentralized dynamic competitive equilibrium is a list of sequences $\left\{c_{t}, i_{t}, k_{t}, p_{t}, q_{t}, h_{t}\right\}_{t=0}^{\infty}$ for the household, a sequence of government purchases and transfers $\left\{g_{t}^{t}, g_{t}^{E}\right\}_{t=0}^{\infty}$, and input prices $\left\{w_{t}, r_{t}\right\}_{t=0}^{\infty}$ such that (i) the household maximizes its utility function subject to its budget constraint; (ii) the representative firm maximizes profit; (iii) government budget is balanced in each period; (iv) pollution and environmental quality follow their laws of motion; (v) all markets clear.

\footnotetext{
${ }^{2}$ From the government constraint it is clear that carbon taxes are an additional burden on labor and capital income.
} 


\section{Data and Model Calibration}

To characterize business cycle fluctuations with pollution and environmental taxation in Bulgaria, we will focus on the period following the introduction of the currency board (19992016). Quarterly data on output, consumption and investment was collected from National Statistical Institute (2018), while the real interest rate is taken from Bulgarian National Bank Statistical Database (2018). The calibration strategy described in this section follows a long-established tradition in modern macroeconomics: first, as in Vasilev (2016), the discount factor, $\beta=0.982$, is set to match the steady-state capital-to-output ratio in Bulgaria, $k / y=13.964$, in the steady-state Euler equation. The labor share parameter, $1-\alpha=0.571$, is obtained as in Vasilev (2017b), and equals the average value of labor income in aggregate output over the period 1999-2016. This value is slightly lower as compared to other studies on developed economies, due to the overaccumulation of physical capital, which was part of the ideology of the totalitarian regime, which was in place until 1989. Next, the average income tax rate was set to $\tau^{y}=0.1$. This is the average effective tax rate on income between 1999-2007, when Bulgaria used progressive income taxation, and equal to the proportional income tax rate introduced as of 2008. Similarly, the tax rate on consumption is set to its value over the period, $\tau^{c}=0.2$. Carbon tax rate was set to its average effective rate $\tau^{E}=0.024$, measured as the average tax payment relative to firm's output value in data, and spending on abatement is on average $g^{E}=0.01$, or one percent of aggregate output (NSI 2017).

Next, the relative weight attached to the utility out of leisure in the household's utility function, $\theta=1.243$, is calibrated to match that in steady-state consumers would supply onethird of their time endowment to working. This is in line with the estimates for Bulgaria (Vasilev 2017a) as well over the period studied. The relative weight attached to environmental quality, $\gamma=0.25$, which is in line with the weight attached to public goods in Bulgaria (Vasilev 2018a). Next, the depreciation rate of physical capital in Bulgaria, $\delta^{k}=0.013$, was taken from Vasilev (2016). It was estimated as the average quarterly depreciation rate over the period 1999-2014.

The steady-state level of environmental quality, $\bar{q}$ is normalized to unity, as in Angelopoulos 
et al. (2013). The degree of persistence of environmental quality is also set to a high value, $\delta^{q}=0.9$, as environmental quality is not just something that pertains to Bulgarian territory. Next, since we do not have any data on the efficiency of abatement technology, we normalize $\nu=1$ as in Economides and Phillipopoulos (2008); In other words the cleaning technology is identical to the government spending on abatement, which is not a very strong assumption. Next, for pollution technology, $\phi=0.067$ was set as the average ratio of carbon dioxide emissions to output.

Table 1: Model Parameters

\begin{tabular}{llll}
\hline \hline Parameter & Value & Description & Method \\
\hline$\beta$ & 0.982 & Discount factor & Calibrated \\
$\alpha$ & 0.429 & Capital Share & Data average \\
$1-\alpha$ & 0.571 & Labor Share & Calibrated \\
$\theta$ & 1.243 & Relative weight attached to leisure & Calibrated \\
$\gamma$ & 0.250 & Relative weight attached to env. quality & Set \\
$\delta^{k}$ & 0.013 & Depreciation rate on physical capital & Data average \\
$\delta^{q}$ & 0.900 & Persistence, environmental quality & Set \\
$\tau^{y}$ & 0.100 & Average tax rate on income & Data average \\
$\tau^{E}$ & 0.024 & Average tax rate on production & Data average \\
$\tau^{c}$ & 0.200 & VAT/consumption tax rate & Data average \\
$A$ & 0.604 & Steady-state value of TFP process & Calibrated \\
$q$ & 1.000 & Steady-state value of env.quality & Set \\
$\nu$ & 1.000 & Efficiency, abatement spending & Set \\
$\phi$ & 0.067 & Steady-state pollution technology & Data Average \\
\hline
\end{tabular}

\section{$4 \quad$ Steady-State}

Once the values of model parameters were obtained, the steady-state equilibrium system solved, the "big ratios" can be compared to their averages in Bulgarian data. The results are reported in Table 2 on the next page. The steady-state level of output was normalized to unity (hence the level of technology $A$ differs from one, which is usually the normalization 
done in other studies), which greatly simplified the computations. Next, the model overestimates consumption-to-output, as there is no government consumption in the model. The investment ratio is also closely approximated, despite the closed-economy assumption. The shares of income are also identical to those in data, which is an artifact of the assumptions imposed on functional form of the aggregate production function. The after-tax return, where $\bar{r}=\left(1-\tau^{y}\right) r-\delta$ is also relatively well-captured by the model.

Table 2: Data Averages and Long-run Solution

\begin{tabular}{lllll}
\hline \hline Variable & Description & Data & Model & Moment matched \\
\hline$y$ & Steady-state output & $\mathrm{N} / \mathrm{A}$ & 1.000 & - (normalization) \\
$c / y$ & Consumption-to-output ratio & 0.624 & 0.815 & $c / y=1-\frac{i}{y}-\frac{g^{E}}{y}$ \\
$i / y$ & Investment-to-output ratio & 0.201 & 0.175 & $i=\frac{\delta k}{y}$ \\
$k / y$ & Capital-to-output ratio & 13.96 & 13.96 & avg. $k / y$ in data \\
$g^{E} / y$ & Govt. spending share on abatement & 0.010 & 0.010 & avg. $g^{E} / y$ in data \\
$w h / y$ & Labor income-to-output ratio & 0.571 & 0.571 & labor share $(1-\alpha)$ \\
$r k / y$ & Capital income-to-output ratio & 0.429 & 0.429 & capital share $(\alpha)$ \\
$h$ & Share of time spent working & 0.333 & 0.333 & leisure weight $(\theta)$ \\
$\bar{r}$ & After-tax net return on capital & 0.014 & 0.016 & discount factor $(\beta)$
\end{tabular}

\section{The Ramsey problem (Optimal fiscal policy under full commitment)}

In this section, we solve for the optimal fiscal policy scenario under full commitment and no externality. More specifically, the government will be modelled as a benevolent planner, who has the same preferences as the people in the economy, i.e. it will choose to maximize the household's utility function, while at the same time taking into account the optimality conditions by both the household and the firm, or the equations describing the DCE. ${ }^{3}$ The fiscal

\footnotetext{
${ }^{3}$ Note that when the household and the firm are making optimal choices, they are taking all fiscal policy variables as given. Also note that the benevolent government treats everyone the same, i.e., we have already imposed the symmetry in the constraints.
} 
instruments at government's disposal are consumption and income tax rate, carbon tax rate, and the level of public spending on pollution abatement. ${ }^{4}$ In this section we allow only for distortionary, or proportional, taxes, thus the optimal allocations are only "second-best." 5 In addition, it will be assumed that the government can also fully and credibly commit to the future sequence of taxes and spending until the end of the optimization period, so the policy is time-consistent.

Under the Ramsey framework, the choice variables for the government are $\left\{c_{t}, g_{t}^{E}, h_{t}, q_{t}, k_{t+1}\right.$, $\left.w_{t}, r_{t}\right\}_{t=0}^{\infty}$ plus the tax rates $\left\{\tau_{t}^{c}, \tau_{t}^{y}, \tau_{t}^{E}\right\}_{t=0}^{\infty}$. The initial conditions for the state variables $\left\{k_{0}, q_{0}\right\}$, the sequence of government transfers $\left\{g_{t}^{t}\right\}_{t=0}^{\infty}$, and the processes followed by total factor productivity and pollution productivity $\left\{A_{t}, \phi_{t}\right\}_{t=0}^{\infty}$, are all taken as given. The optimal policy problem is then recast as a setup where the government chooses after-tax input prices $\tilde{r}_{t}$ and $\tilde{w}_{t}$ directly, where ${ }^{6}$

$$
\begin{gathered}
\tilde{r}_{t} \equiv\left(1-\tau_{t}^{y}\right) r_{t} \\
\tilde{w}_{t} \equiv\left(1-\tau_{t}^{y}\right) w_{t} .
\end{gathered}
$$

In addition, the Ramsey planner will be internalizing the pollution externality in the firm's profit maximization.

Next, government budget constraint is now represented by

$$
\tau_{t}^{c} c_{t}+\left(1+\tau_{t}^{E}\right) A k_{t}^{\alpha} h_{t}^{1-\alpha}-\tilde{r}_{t} k_{t}-\tilde{w}_{t} h_{t}=g_{t}^{E}+g_{t}^{t}
$$

The Ramsey problem then becomes

$$
\max _{\left\{c_{t}, h_{t}, k_{t+1}, g_{t}^{E}, \tau_{t}^{E}, \tilde{w}_{t}, \tilde{r}_{t}, \tau_{t}^{c}\right\}} E_{0} \sum_{t=0}^{\infty} \beta^{t}\left\{\ln c_{t}+\theta \ln \left(1-h_{t}\right)+\gamma \ln q_{t}\right\}
$$

\footnotetext{
${ }^{4}$ Note that the government transfers will be held fixed at the level computed from the equilibrium under the exogenous policy case.

${ }^{5}$ In case the government is allowed to use lump-sum taxation, it can achieve the first-best (Pareto) allocation.

${ }^{6}$ Note that $r_{t}, w_{t}$ were functions of $\tau_{t}^{E}$.
} 
s.t.

$$
\begin{array}{r}
\frac{1}{c_{t}}=\beta E_{t} \frac{1}{c_{t+1}}\left[1-\delta^{k}+\tilde{r}_{t+1}\right] \\
\frac{\theta}{1-h_{t}}=\frac{\tilde{w}_{t}}{\left(1+\tau_{t}^{c}\right) c_{t}} \\
A k_{t}^{\alpha} h_{t}^{1-\alpha}=c_{t}+k_{t+1}-\left(1-\delta^{k}\right) k_{t}+g_{t}^{E} \\
\tau_{t}^{c} c_{t}+\left(1+\tau^{E}\right) A k_{t}^{\alpha} h_{t}^{1-\alpha}-\tilde{r}_{t} k_{t}-\tilde{w}_{t} h_{t}=g_{t}^{E}+g_{t}^{t} \\
q_{t+1}=\left(1-\delta^{q}\right) \bar{q}+\delta^{q} q_{t}-\phi A k_{t}^{\alpha} h_{t}^{1-\alpha}+\nu g_{t}^{E}
\end{array}
$$

In order to solve the previous problem we set up the corresponding Lagrangean,

$$
\begin{array}{r}
\mathcal{L}=\max _{\left\{c_{t}, \eta_{t}, k_{t+1}, g_{t}^{c}, \tilde{w}_{t}, \tilde{r}_{t}, \tau_{t}^{c}\right\}} E_{0} \sum_{t=0}^{\infty} \beta^{t}\left\{\ln c_{t}+\theta \ln \left(1-h_{t}\right)+\gamma \ln q_{t}\right. \\
+\lambda_{t}^{1}\left[-c_{t+1}+c_{t}\left(1-\delta^{k}+\tilde{r}_{t+1}\right)\right]+\lambda_{t}^{2}\left[\theta\left(1+\tau_{t}^{c}\right) c_{t}-\tilde{w}_{t}\left(1-h_{t}\right)\right] \\
+\lambda_{t}^{3}\left[A k_{t}^{\alpha} h_{t}^{1-\alpha}-c_{t}-k_{t+1}+\left(1-\delta^{k}\right) k_{t}-g_{t}^{E}\right] \\
+\lambda_{t}^{4}\left[\tau_{t}^{c} c_{t}+\left(1+\tau_{t}^{E}\right) A k_{t}^{\alpha} h_{t}^{1-\alpha}-\tilde{r}_{t} k_{t}-\tilde{w}_{t} h_{t}-g_{t}^{E}-g_{t}^{t}\right] \\
\left.+\lambda_{t}^{5}\left[-q_{t+1}+\left(1-\delta^{q}\right) \bar{q}+\delta^{q} q_{t}-\phi A k_{t}^{\alpha} h_{t}^{1-\alpha}+\nu g_{t}^{E}\right]\right\}
\end{array}
$$

The optimality conditions are as follows: ${ }^{7}$

$$
\begin{aligned}
c_{t}: & -\frac{\lambda_{t-1}^{1}}{\beta}+\frac{1}{c_{t}}+\lambda_{t}^{1}\left(1-\delta^{k}+\tilde{r}_{t+1}\right)+\lambda_{t}^{2} \theta\left(1+\tau_{t}^{c}\right)-\lambda_{t}^{3}+\lambda_{t}^{4} \tau_{t}^{c}=0 \\
h_{t}: & \frac{\theta}{1-h_{t}}+\lambda_{t}^{2} \tilde{w}_{t}+\lambda_{t}^{3}\left(1+\tau_{t}^{E}\right)(1-\alpha) \frac{y_{t}}{h_{t}}-\lambda_{t}^{4} \tilde{w}_{t} \\
& +\lambda_{t}^{4}\left(1+\tau_{t}^{E}\right)(1-\alpha) \frac{y_{t}}{h_{t}}-\lambda_{t}^{5} \phi \frac{(1-\alpha) y_{t}}{h_{t}}=0 \\
k_{t+1}: & -\frac{\lambda_{t-1}^{3}}{\beta}+\lambda_{t}^{3}\left[r_{t}+1-\delta\right]+\lambda_{t}^{4}\left[\frac{\left(1+\tau_{t}^{E}\right)}{1-\tau_{t}^{E}} r_{t}-\tilde{r}_{t}\right]-\lambda_{t}^{5} \phi \frac{\alpha y_{t}}{k_{t}}=0 \\
g_{t}^{E}: & \lambda_{t}^{3}+\lambda_{t}^{4}=\nu \lambda_{t}^{5} \\
\tau_{t}^{c}: & \lambda_{t}^{2} \theta c_{t}+\lambda_{t}^{4} c_{t}=0 \\
\tilde{r}_{t}: & \frac{\lambda_{t-1}^{1} c_{t-1}}{\beta}=\lambda_{t}^{4} k_{t} \\
q_{t} \quad: & \frac{1}{q_{t}}+\frac{\lambda_{t-1}^{5}}{\beta}+\lambda_{t}^{5} \delta^{q}=0 .
\end{aligned}
$$

\footnotetext{
${ }^{7}$ Note that by choosing capital, hours, and abatement spending, the Ramsey planner chooses environmental quality optimally as well.
} 


$$
\begin{aligned}
\lambda_{t}^{1} \quad: \quad c_{t+1}=c_{t}\left(1-\delta^{k}+\tilde{r}_{t+1}\right) \\
\lambda_{t}^{2}: \quad \theta\left(1+\tau_{t}^{c}\right) c_{t}=\tilde{w}_{t}\left(1-h_{t}\right) \\
\lambda_{t}^{3} \quad: \quad A k_{t}^{\alpha} h_{t}^{1-\alpha}=c_{t}+k_{t+1}-\left(1-\delta^{k}\right) k_{t}+g_{t}^{E} \\
\lambda_{t}^{4} \quad: \quad \tau_{t}^{c} c_{t}+\left(1+\tau_{t}^{E}\right) A k_{t}^{\alpha} h_{t}^{1-\alpha}=\tilde{r}_{t} k_{t}+\tilde{w}_{t} h_{t}+g_{t}^{E}+g_{t}^{t} \\
\lambda_{t}^{5} \quad: \quad q_{t+1}=\left(1-\delta^{q}\right) \bar{q}+\delta^{q} q_{t}-\phi A k_{t}^{\alpha} h_{t}^{1-\alpha}+\nu g_{t}^{E}
\end{aligned}
$$

We can also add the equations for the auxiliary variables, namely

$$
\begin{aligned}
y_{t} & =A k_{t}^{\alpha} h_{t}^{1-\alpha} \\
y_{t} & =c_{t}+k_{t+1}-\left(1-\delta^{k}\right) k_{t}+g_{t}^{E} \\
i_{t} & =k_{t+1}-\left(1-\delta^{k}\right) k_{t} \\
r_{t} & =\left(1-\tau_{t}^{E}\right) \alpha \frac{y_{t}}{k_{t}} \\
w_{t} & =\left(1-\tau_{t}^{E}\right)(1-\alpha) \frac{y_{t}}{h_{t}}
\end{aligned}
$$

\subsection{Steady-state Ramsey with pollution and carbon tax}

In this section we focus on the steady-state Ramsey allocations. ${ }^{8}$ Evaluating optimality conditions and constraints in steady-state produces the following: When the planner internalizes the pollution externality, carbon tax is set to $\tau^{E}=\phi /(1+\phi)$ to offset the negative effect of pollution on output. Note that since in steady-state $\frac{\lambda^{4}}{\beta}=\lambda^{4}[r+1-\delta]$, it follows that $r=\tilde{r}$, which means that $\tau^{y}=0$. But then it follows that $w=\tilde{w}$, since both factors of production are taxed at the same rate. Consumption tax rate is again residually determined from the government budget constraint. In other words, consumption tax revenue needs to equal the steady-state level of government transfers. Table 3 on the next page reports the results and compares the observed vs. the optimal fiscal policy regime.

Compared to the exogenous policy case, under optimal fiscal policy the benevolent government sets the income tax rate to zero, as in Judd (1985), Chamley (1986), and Zhu (1992), which leads to a higher capital in steady-state. That drives up after tax wages, and hours are higher. Steady-state output under the second-best equilibrium is also higher, the same upward change is observed in investment, and consumption. The real interest rate is also

\footnotetext{
${ }^{8}$ IRFs under both regimes identical, focus on steady-state/long-run allocations, analytical results.
} 
Table 3: Exogenous vs. Ramsey policy

\begin{tabular}{lllll}
\hline \hline Variable & Description & Data & Exo. policy & Ramsey \\
\hline$y$ & Steady-state output & $\mathrm{N} / \mathrm{A}$ & 1.000 & 1.061 \\
$c / y$ & Consumption-to-output ratio & 0.674 & 0.815 & 0.713 \\
$i / y$ & Investment-to-output ratio & 0.201 & 0.175 & 0.224 \\
$k / y$ & Capital-to-output ratio & 3.491 & 3.491 & 4.475 \\
$g^{E} / y$ & Government cons-to-output ratio & 0.010 & 0.010 & 0.063 \\
$w h / y$ & Labor income-to-output ratio & 0.571 & 0.571 & 0.571 \\
$r k / y$ & Capital income-to-output ratio & 0.429 & 0.429 & 0.429 \\
$h$ & Share of time spent working & 0.333 & 0.333 & 0.354 \\
$\tilde{r}$ & After-tax net return on capital & 0.056 & 0.057 & 0.046 \\
$q$ & Steady-state environmental quality & $\mathrm{N} / \mathrm{A}$ & 1.000 & 1.200 \\
$\tau^{E}$ & Carbon tax rate & 0.024 & 0.024 & 0.063 \\
$\tau^{y}$ & Income tax rate & 0.100 & 0.100 & 0.000 \\
$\tau^{c}$ & Consumption tax rate & 0.200 & 0.200 & 0.098 \\
$\xi$ & Welfare gain & - & 0.000 & 0.135 \\
\hline
\end{tabular}

lower which is a function of the higher capital stock, which overcompensates for the absence of income taxation.

The new channel is the pollution channel. Indeed, output is higher under Ramsey, which could lead to more pollution. With the appropriately chosen carbon tax (which is now three times higher as compared to the exogenous policy case), and a producer that internalizes the pollution externality, the net effect on environmental quality is positive, as government now spends six time more on abatement. In a way, the carbon tax adds to the burden on capital and labor, and drives down wages and the real interest rate. In essence, what matters in the model is the total tax burden. Even though the carbon tax is higher, that serves a specific purpose, to tax pollution at the source, while the "general-purpose" income tax is abolished, so the net burden on capital is twice lower.

Finally, note that the only source of revenue is consumption taxation (the revenue from 
the carbon tax is spent on abatement). Since it is a non-distortionary tax, in the Ramsey framework its rate will be determined residually to achieve government budget balance. Since public consumption is now lower, and the level of government transfers is held equal to its level from the exogenous policy, the consumption tax rate can drop by half to less than 10\%. This feeds back into more hours worked, as described above.

Lastly, there is a substantial improvement of welfare that can be realized by moving from the equilibrium under the exogenous policy regime to the equilibrium with optimal fiscal policy. The exogenous-policy equilibrium features several inefficiencies driven by the presence of not only taxes and public goods, but also externalities due to the presence of pollution and utility-enhancing environmental quality. Welfare gain, measured in terms of additional consumption $(\xi)$, is almost 0.135 , which means that in order to make people as well off as they are under the Ramsey regime, the benevolent government needs to increase the steady-state consumption under the exogenous policy case by approximately one-seventh to make them indifferent to the allocation under Ramsey regime. Overall, our results are new and could be of interest to policy makers, as previous research had ignored the important dimension of taxing pollution and spending on pollution abatement, and their relevance for fiscal policy, and economic activity.

\section{Conclusions}

This paper characterized optimal fiscal policy in the presence of pollution and carbon taxes, and government spending on pollution abatement, and evaluated it relative to the exogenous (observed) one. The results were evaluated in light of the optimal taxation of dirty production and the optimal provision of environment cleaning spending, and the effect of that specific fiscal policy on the level of utility-enhancing environmental quality. To this end, a dynamic general-equilibrium model, calibrated to Bulgarian data (1999-2016), was set up with a richer public finance side. Bulgarian economy was chosen as a case study for a transition economy with an unreformed and polluting industry. The main findings from the computational experiments performed in the paper are: (i) The optimal steady-state income tax rate is zero; (ii) The benevolent Ramsey planner provides the efficient amount of the utility- enhancing 
environmental quality, which are now twenty percent higher; (iii) The optimal level of carbon taxes is three times higher, and the optimal level of abatement spending is six times higher; (iv) The optimal steady-state consumption tax is twice lower, as compared to the exogenous policy case.

\section{References}

Angelopoulos, K., Economides, G. and A. Phillipopoulos (2013) "First- and second-best allocations under economic and environmental uncertainty," International Tax and Public Finance 20: 360-80.

Angelopoulos, K., Economides, G., and A. Phillipopoulos (2010) "Which is the best environment policy? Taxes, permits and rules under economic and environmental uncertainty," Working Paper No. 2980, CES-Ifo, Munich, Germany.

Bulgarian National Bank (2017) Bulgarian National Bank Statistics. Available on-line at www.bnb.bg. Accessed on Oct. 21, 2017.

Canova, F. (2007) Methods for Applied Macroeconomic Research. Princeton University Press: Princeton, NJ.

Chamley, C. (1986) "Optimal taxation of capital income in general equilibrium with infinite lives," Econometrics 54: 607-22.

Chari, V.V. and P. Kehoe. (1994) "Optimal Fiscal Policy in a Real Business Cycle Model," Journal of Political Economy, vol.102, no.4 (Aug.), pp. 617-652.

Chari, V.V., Kehoe, P. (1999) "Optimal fiscal and monetary policy," in: Taylor, J.B., Woodford, M. (Eds.) Handbook of Macroeconomics vol.1. North-Holland: Amsterdam, the Netherlands. 
Economides, G., and A. Phillipopoulos (2008) "Growth enhancing policy is the means to sustain the environment," Review of Economic Dynamics 11: 207-219.

Heutel, G. (2012) "How should environmental policy respond to business cycles? Optimal policy under persistent productivity shocks," Review of Economic Dynamics 15: 244-64.

Judd, K. (1985) "Redistributive Taxation in a Simple Perfect Foresight Model," Journal of Public Economics, vol. 28, pp. 59-83.

National Statistical Institute (2017) Aggregate Statistical Indicators. Available on-line at www.nsi.bg. Accessed on Oct. 21, 2017.

Vasilev, A.Z. (2018a) "Optimal fiscal policy in the presence of VAT evasion: The case of Bulgaria," Czech Journal of Economics and Finance, forthcoming.

Vasilev, A.Z. (2018b) "A Real-Business-Cycle model with pollution and environmental taxation: the case of Bulgaria," Journal of Environmental Economics and policy, forthcoming.

Vasilev, A. Z. (2017a) "Business Cycle Accounting: Bulgaria after the introduction of the currency board arrangement (1999-2014), European Journal of Comparative Economics, vol.14, No.2, pp. 197-219.

Vasilev, A.Z. (2017b) "VAT Evasion in Bulgaria: A General-Equilibrium Approach," Review of Economics and Institutions, Vol. 8, No.2, pp. 2-17.

Vasilev, A. (2016) "Search and matching frictions and business cycle fluctuations in Bulgaria," Bulgarian Economic Papers BEP 03-2016, Center for Economic Theories and Policies, Sofia University St. Kliment Ohridski, Faculty of Economics and Business Administration, Sofia, Bulgaria.

Vasilev, A. (2015a) "Welfare effects of flat income tax reform: the case of Bulgaria," Eastern 
European Economics 53(2): 205-220, July.

Vasilev, A. (2015b) "Welfare gains from the adoption of proportional taxation in a generalequilibrium model with a grey economy: the case of Bulgaria's 2008 flat tax reform," Economic Change and Restructuring, vol. 48(2), pp. 169-185.

Zhu, X. (1992) "Optimal Fiscal Policy in a Stochastic Growth Model," Journal of Monetary Economics, vol. 58, pp. 250-289. 